\title{
Characteristics of cardiovascular responses to an orthostatic challenge in trained spinal cord-injured individuals
}

\author{
Masahiro Itoh ${ }^{*}$, Masako Yamaoka Endo ${ }^{2,4}$, Tatsuya Hojo ${ }^{3}$, Miho Yoshimura ${ }^{3}$ and Yoshiyuki Fukuoka ${ }^{4,5}$
}

\begin{abstract}
Background: We investigated cardiovascular responses to an orthostatic challenge in trained spinal cord-injured $(\mathrm{SCl})$ individuals compared to able-bodied (AB) individuals.

Methods: A total of 23 subjects participated, divided into three groups: seven were trained as spinal cord-injured (Tr-SCl) individuals, seven were able-bodied individuals trained as runners (Tr-AB), and nine were untrained able-bodied individuals (UnTr-AB). We measured the cardiovascular autonomic responses in all three groups during each 5-min head-up tilt (HUT) of $0^{\circ}, 40^{\circ}$, and $80^{\circ}$. Stroke volume (SV), heart rate (HR), and cardiac output (Qc) as cardiovascular responses were measured by impedance cardiography. Changes in deoxyhemoglobin $(\Delta[\mathrm{HH}])$ and total hemoglobin $\left(\Delta\left[\mathrm{Hb}_{\text {tot }}\right]\right)$ concentrations of the right medial gastrocnemius muscle were measured using nearinfrared spectroscopy (NIRS).

Results: As the HUT increased from $0^{\circ}$ to $80^{\circ}, \mathrm{Tr}$-SCl group showed less change in SV at all HUT levels even if HR increased significantly. Mean arterial pressure (MAP) also did not significantly increase as tilting increased from $0^{\circ}$ to $80^{\circ}$. Regarding peripheral vascular responses, the alterations of $\Delta\left[\mathrm{Hb}_{\text {tot }}\right]$ from $0^{\circ}$ to $80^{\circ}$ were less in Tr-SCl group compared to AB individuals.

Conclusion: There is a specific mechanism whereby blood pressure is maintained during a HUT in Tr-SCl group with the elicitation of peripheral vasoconstriction and the atrophy of the vascular vessels in paraplegic lower limbs, which would be associated with less change in SV in response to an orthostatic challenge.
\end{abstract}

Keywords: Orthostatic challenge, Spinal cord injury, Cardiovascular responses, Near-infrared spectroscopy

\section{Background}

A spinal cord injury (SCI) leads to dramatic central and peripheral cardiovascular adaptation. Decreases in cardiac output (Qc) and dimension have been reported in individuals with SCIs $[1,2]$. Below the level of SCI lesions, increased peripheral vascular resistance [3], reduced peripheral capillarization [4], and decreased conduit artery diameters have also been observed [5-7]. These findings indicate that less blood pooling may occur in paraplegic lower limbs. However, in individuals with a SCI, orthostatic hypotension resulting from an acute or progressive decline in blood pressure (BP) $>10-15 \mathrm{mmHg}$ in an erect

\footnotetext{
* Correspondence: ito@gpo.kumamoto-u.ac.jp

${ }^{1}$ Department of Physiology, Kumamoto University Graduate School of Life

Sciences, 4-24-1, Kuhonji Chuou-ku, Kumamoto 862-0976, Japan

Full list of author information is available at the end of the article
}

position during standing or tilting may result in poor tolerance for standing, thus prolonging the rehabilitation time and worsening the deleterious effects of remaining immobile [8]. The mechanism that underlies maintenance of BP must therefore play an important role in the tilt-induced increase in leg vascular tone in SCI patients corresponding to reduced central circulatory hypokinesis.

By contrast, despite the absence of central sympathetic control of limb vascular adjustment, SCI patients showed remarkable orthostatic tolerance during posture stress and their BP level was maintained during orthostatic challenges by augmented local vasoconstriction, most likely as part of the myogenic response [9]. Theisen et al. also showed a vasoconstriction response during leg dependency in paraplegia, suggesting that a veno-arteriolar axon reflex (VAR) or myogenic activity was present in spinal

(C) The Author(s). 2018 Open Access This article is distributed under the terms of the Creative Commons Attribution 4.0 International License (http://creativecommons.org/licenses/by/4.0/), which permits unrestricted use, distribution, and 
cord-injured individuals [10]. It is thus still unknown whether the blood pressure of individuals with SCIs can be maintained during an orthostatic challenge (as ablebodied healthy subjects can).

It has been demonstrated that individuals with aerobically fit paraplegia had significantly higher maximal cardiorespiratory fitness compared to individuals with sedentary lifestyle paraplegia [11]. During an incremental arm exercise, individuals with aerobically fit paraplegia developed a 34-44\% Qc advantage and had a greater stroke volume (SV) relative to their inactive counterparts [12]. If wheelchair exercise training would induce greater Qc and mitigate reduced central circulatory hypokinesis, the arterial inflow of blood into paraplegic limbs might be augmented. In addition, some degree of resultant blood pooling could occur when the individual is in an upright position. However, it is not known whether trained SCI individuals can maintain their BP level in response to an orthostatic challenge. Near-infrared spectroscopy (NIRS) is a useful tool that can observe alterations in the microvascular blood flow into skeletal muscles when a subject is in a resting state. The present study comprehensively evaluated the interaction of central and peripheral circulation for BP maintenance in trained SCI individuals.

\section{Methods}

\section{Participants and aerobic fitness}

Seven trained SCI male individuals (Tr-SCI $34.1 \pm$ 4.9 years old, body weight [BW] $58.9 \pm 3.7 \mathrm{~kg}$, VO2 max $27.3 \pm 1.72 \mathrm{ml} \mathrm{kg}^{-1} \mathrm{~min}^{-1}$ during arm cranking, lesion level: thoracic vertebrae 6th (Th6) - lumbar vertebrae 1st (Lu1)) underwent a continuous wheelchair-basketball training program (basic skill and game training, approximately $2 \mathrm{~h}$ /day, 3 days/week) with an intensity of approximately $80 \%$ HR peak [1]. None of the $\mathrm{Tr}-\mathrm{SCI}$ group took any antihypertensive agents. The thickness of the subcutaneous adipose tissue (ATT) in the medial gastrocnemius muscle region was determined by B-mode ultrasound (model Logiq 400; GE-Yokogawa Medical Systems, Tokyo) with the Tr-SCI group in the sitting position. All individuals had incomplete lesions classified as American Spinal Injury Association [ASIA] class B [13]. The physical characteristics of the $\mathrm{Tr}-\mathrm{SCI}$ group, the amount of time since they incurred their SCIs, and their time spent practicing basketball are shown in Table 1.

Seven healthy trained able-bodied male individuals (Tr-AB $19.4 \pm 0.3$ years old, $168.9 \pm 1.8 \mathrm{~cm}$, BW $56.6 \pm$ $1.7 \mathrm{~kg}$, VO2 max $60.9 \pm 1.61 \mathrm{ml} \mathrm{kg}^{-1} \mathrm{~min}^{-1}$ during running) and nine healthy untrained able-bodied male individuals (UnTr-AB; $21.0 \pm 0.4$ years old, $170.5 \pm 1.1 \mathrm{~cm}$, BW $62.8 \pm 2.1 \mathrm{~kg}, \mathrm{VO} 2 \max$ no measurement) constituted the two other groups tested. The individuals in the $\mathrm{Tr}-\mathrm{AB}$ group were university level long-distance runners who had run approximately $300 \mathrm{~km}$ month $^{-1}$ each over the prior 10 years. The individuals in the UnTr-AB group were university students who did not engage in any regular sports activity. All $\operatorname{Tr}-\mathrm{AB}$ and $\mathrm{UnTr}-\mathrm{AB}$ group had no history of cardiovascular diseases and were healthy as indicated by medical history, physical examination, BP $(<140 / 90 \mathrm{mmHg})$, and 12-lead electrocardiogram (ECG). The experimental protocol was approved by the ethics committee of the Institutional Review Board of the Prefectural University of Kumamoto. All subjects provided written consent for their participation after they were fully informed about the study. The investigation was performed in compliance with the Declaration of Helsinki.

\section{Tilt table protocol}

All three groups of individuals underwent experimental sessions (15 min) using a customized head-up tilt (HUT; Ishinuki steel Co., Kumamoto) table from $0^{\circ}$ (supine position), to $40^{\circ}$ (tilting position), to $80^{\circ}$ (standing position) for $5 \mathrm{~min}$. The body in the $\mathrm{Tr}-\mathrm{SCI}$ group was fixed on three portions of chest, upper limbs, and lower limbs by three clinical belts with the strong hook-and-loop fastener from both sides of the tilt bed. The Tr-SCI group could stand the foot plate in their shoes. Their shoes produced friction on foot plate to prevent their slip. Tilt gradients were changed slowly to prevent ankle

Table 1 Physical characteristics and basketball career length for trained spinal cord-injured individuals

\begin{tabular}{|c|c|c|c|c|c|c|}
\hline Subjects & Sex & Age (years) & Weight (kg) & Time since injury (months) & Length of basketball career (years) & Level of injury (spinal cord lesion) \\
\hline$a$ & Male & 24 & 50 & 75 & 4.5 & Th12 and Lu1 \\
\hline b & Male & 27 & 52 & 84 & 5.0 & Th12 \\
\hline c & Male & 52 & 70 & 385 & 31.0 & Lu1 \\
\hline$d$ & Male & 20 & 73 & 38 & 2.0 & Th11 \\
\hline e & Male & 51 & 51 & 319 & 24.0 & Th11 and Th12 \\
\hline$f$ & Male & 37 & 64 & 128 & 9.0 & Th7 \\
\hline g & Male & 28 & 52 & 59 & 5.0 & Th6 \\
\hline mean $\pm S E$ & & $34.1 \pm 4.9$ & $58.9 \pm 3.7$ & $155.4 \pm 52.3$ & $11.5 \pm 4.3$ & \\
\hline
\end{tabular}


clonus in the Tr-SCI group. During three steps of HUT, we assumed that that energy expenditure in the individuals was almost constant. On each data collection day, individuals reported to the laboratory at least $2 \mathrm{~h}$ after their last meal. They were asked to avoid caffeine, alcohol ingestion, and strenuous exercise for $24 \mathrm{~h}$ before the test. The temperature and relative humidity of the laboratory were maintained at $25{ }^{\circ} \mathrm{C}$ and $50 \%$, respectively.

\section{Measurements and data analysis}

The central hemodynamic values of SV and Qc were continuously determined by an impedance method [14-16] using a computer-based automated technique with an impedance plethysmograph (AI-601G, Nihon Koden, Tokyo). Four disposable electrodes were placed on the neck and chest. The analog change in impedance $(\Delta \mathrm{Z})$ data and the voltage changes in the thorax were detected.

To avoid the effects of respiration and movement on impedance signals, we averaged the $\Delta \mathrm{Z}$ values over three heartbeats, with the R-wave from the ECG serving as the trigger [17]. The Qc was estimated noninvasively by measuring the changes in electrical impedance $\left(Z_{0}\right)$ transthoracically. Changes in transthoracic impedance have an inverse relationship to changes in the volume of fluid in the thorax. The SV was calculated as follows: $\mathrm{SV}=\rho \times\left(L^{2} / Z_{0}^{2}\right) \times \mathrm{ET} \times\left(\mathrm{dZ} / \mathrm{dt}_{\max }\right)$, where $\mathrm{SV}$ indicates the stroke volume; $\rho$, the resistivity of the conductor; $L^{2} /$ $Z_{0}^{2}$, the thoracic impedance $(\Omega)$, which is inversely proportional to the amount of fluid (ohms) in the thorax; $\mathrm{ET}$, the ejection time; and $\mathrm{dZ} / \mathrm{dt}_{\max }$, the maximum deflection $(\Omega / s)$ of the $d Z / d t$ waveform during the ET. Trained SCI patients had already the information of blood examination data before this experiment. The mean value of $H c t$ was $38.5 \pm 3.43$ (SD) \%. As the rho was calculated by Geddes and Sadler equation (rho = $53.2 \mathrm{e}^{0.022 \mathrm{Hct}}$ ), the averaged values in rho was $124.4 \pm$ $9.4 \Omega \mathrm{cm}$. Otherwise, the value of rho in both $A B$ groups was constant of $135 \Omega \mathrm{cm}$. Both $\mathrm{AB}$ groups did not collect blood for analysis of Hct.

The beat-by-beat heart rate (HR) was continuously monitored by ECG (AT-601G; Nihon Kohden, Tokyo), which was conducted using transistor-transistor logic signal intervals synchronized with the $\mathrm{R}$-wave of the ECG by CM5 leads. All data were adopted using a data acquisition system (PowerLab system, A/D Instruments, Castle Hill, NSW, Australia) with an interval resolution of $2 \mathrm{~ms}$ (i.e., sampling interval at $500 \mathrm{~Hz}$ ). A customized software program was used to identify a stable and noise-independent fiducial point on all $\mathrm{R}$-waves for each recording.

Systolic and diastolic blood pressure (SBP, DBP) values were measured using a sphygmomanometer (DM-500, Muranaka, Osaka) at heart level on the upper right arm as it rested alongside the subject's body. The BP was measured twice at $2 \mathrm{~min}$ and $4 \mathrm{~min}$ at each gradient. The total peripheral resistance (TPR) was calculated when the BP was available. The TPR measure was defined as the mean arterial pressure (MAP) per cardiac output in $\mathrm{mmHg} \mathrm{L} \mathrm{min}^{-1}$. The MAP was calculated using $\mathrm{DBP}$ and SBP, using the formula $\mathrm{MAP}=\mathrm{DBP}+1 / 3$ (SBP - DBP).

The oxygenation and deoxygenation profiles of the right medial gastrocnemius muscle were recorded during the HUT test using continuous-wave NIRS (BOM-L1 TR, Omega Wave, Tokyo). The system monitored the concentration in oxyhemoglobin $\left(\mathrm{HbO}_{2}\right)$, deoxyhemoglobin $(\mathrm{HHb})$, and total hemoglobin $\left(\mathrm{Hb}_{\mathrm{tot}}\right)$, which were calculated from the light attenuation change by using the modified Beer-Lambert law [18]. $\Delta\left[\mathrm{Hb}_{\text {tot }}\right]$ was the sum of $\Delta[\mathrm{HHb}]$ and $\Delta\left[\mathrm{HbO}_{2}\right]$. Pulsed light was emitted at 1-s intervals from the emission probe at four different wavelengths $(775,810,850$, and $910 \mathrm{~nm})$ and was detected, as a function of distance, using a three-segment photodiode detection probe that received NIRS signals at $2 \mathrm{~Hz}$. The distance between the emitter and receiver was $40 \mathrm{~mm}$, and the penetration depth was approx. half of the distance between the emitter and the receiver, i.e., $20 \mathrm{~mm}$. This has been validated in both healthy persons and patients [19] and patients [20,21].

The NIRS data gathered represented the relative concentration changes in the hemoglobin chromophores and were therefore not representative of absolute tissue $\mathrm{O}_{2}$ values. As $\Delta\left[\mathrm{HbO}_{2}\right], \Delta[\mathrm{HHb}]$, and $\Delta\left[\mathrm{Hb}_{\text {tot }}\right]$ were measured as a change from the resting baseline values, the probe gain was zero set prior to testing with the subject at rest in a supine position $\left(0^{\circ}\right)$.

\section{Statistical analysis}

All data are expressed as mean \pm standard error (SE). Two-way analysis of variance (ANOVA) was performed to determine whether the central and peripheral parameters were significantly different during the three stages $\left(0^{\circ}, 40^{\circ}\right.$, and $80^{\circ}$ ) among the three groups (Tr-SCI, Tr- $\mathrm{AB}$, and UnTr-AB). If significant effects of tilt were observed, Fisher's PLSD test was used to evaluate the differences between two trials (vs. 0 gradient degree in each group/vs. $\mathrm{Tr}-\mathrm{AB}$ in each stage). A mixed effects analysis of variance (ANOVA) was used to separately to compare additional significant main (group and HUT) and interaction (group $\mathrm{X}$ HUT) effects of HR and BP to the HUT procedures. A probability $(p)$ value of $<0.05$ was regarded as significant.

\section{Results}

There were statistically significant differences in age between the $\operatorname{Tr}$-SCI and $\operatorname{Tr}-\mathrm{AB}$ groups $\left(F_{(2,20)}=4.28\right.$, $p<0.01)$ and the Tr-SCI and UnTr-AB groups $\left(F_{(2,20)}\right.$ $=3.58, p<0.01$ ). 
The ATT in the medial gastrocnemius muscle region averaged $8.7 \pm 0.8 \mathrm{~mm}$ in the $\mathrm{Tr}$-SCI group. Even though the ATT in the two present $\mathrm{AB}$ groups could not be measured, our recent ATT data in a different study averaged $3.0 \pm 0.8 \mathrm{~mm}$ in runners and $3.9 \pm 1.2 \mathrm{~mm}$ in untrained young subjects (unpubl. observations).

Figure 1 shows the central circulatory responses for HR, SV, and Qc during the HUT tests. Significantly increased HR and inversely decreased SV were proportionally observed in association with increased HUT from $0^{\circ}$ to $80^{\circ}$ in both $\mathrm{AB}$ groups, whereas the $\mathrm{Tr}$-SCI group exhibited no change in SV at any degree of tilt.

In the supine position $\left(0^{\circ}\right)$, the HR in the $\mathrm{Tr}$-SCI group $(73 \pm 6 \mathrm{bpm})$ was significantly greater than that in the $\mathrm{Tr}-\mathrm{AB}$ group $\left(58 \pm 3 \mathrm{bpm}, \quad F_{(2,20)}=3.63, \quad p<0.01\right)$, whereas a significantly lower $\mathrm{SV}$ at $0^{\circ}$ was found in the $\mathrm{Tr}$-SCI group $(78 \pm 9 \mathrm{~mL})$ in comparison with the $\mathrm{Tr}-\mathrm{AB}$ group $\left(104 \pm 11 \mathrm{~mL}, F_{(2,20)}=4.10, p<0.05\right)$ (Fig. 2). The $\mathrm{HR}$ in both the $\mathrm{Tr}-\mathrm{AB}$ and UnTr-AB groups increased significantly with proportionally increased gradients (from $58 \pm 3 \mathrm{bpm}$ to $74 \pm 3 \mathrm{bpm}$ in $\mathrm{Tr}-\mathrm{AB}$; from $64 \pm$ $2 \mathrm{bpm}$ to $91 \pm 4 \mathrm{bpm}$ in UnTr-AB, $F=3.89, F_{(2,20)}=3.63$, $p<0.01$, respectively) (Table 2). The HR in Tr-SCI group also increased significantly with proportionally increased gradients (from $73 \pm 6 \mathrm{bpm}$ to $85 \pm 6 \mathrm{bpm}, F_{(2,20)}=4.10$, $p<0.01$, respectively) (Table 2).

The corresponding $\mathrm{SV}$ in both $\mathrm{AB}$ groups was significantly decreased at $80^{\circ}$ compared to $0^{\circ}$ (from $104 \pm$ $11 \mathrm{~mL}$ to $71 \pm 6 \mathrm{~mL}$ in $\mathrm{Tr}-\mathrm{AB}$; from $93 \pm 6 \mathrm{~mL}$ to $62 \pm$ $4 \mathrm{~mL}$ in UnTr-AB, $F_{(2,20)}=3.89, F_{(2,20)}=3.63, p<0.05$, $p<0.01$, respectively). On the other hand, the $\mathrm{Tr}$-SCI group had a distinct profile in that the SV did not change significantly, even though the HR increased significantly, as the gradient of the tilt table increased (Table 2). The resultant Qc was not significantly different in any group or at any gradient of the tilt table.

Significantly increased MAP values at $80^{\circ}$ in $\mathrm{Tr}-\mathrm{AB}$ group and significantly increased DBP and MAP values were observed at both $40^{\circ}$ and $80^{\circ}$ in UnTr-AB group, whereas no significant differences in SBP, DBP, MAP, or

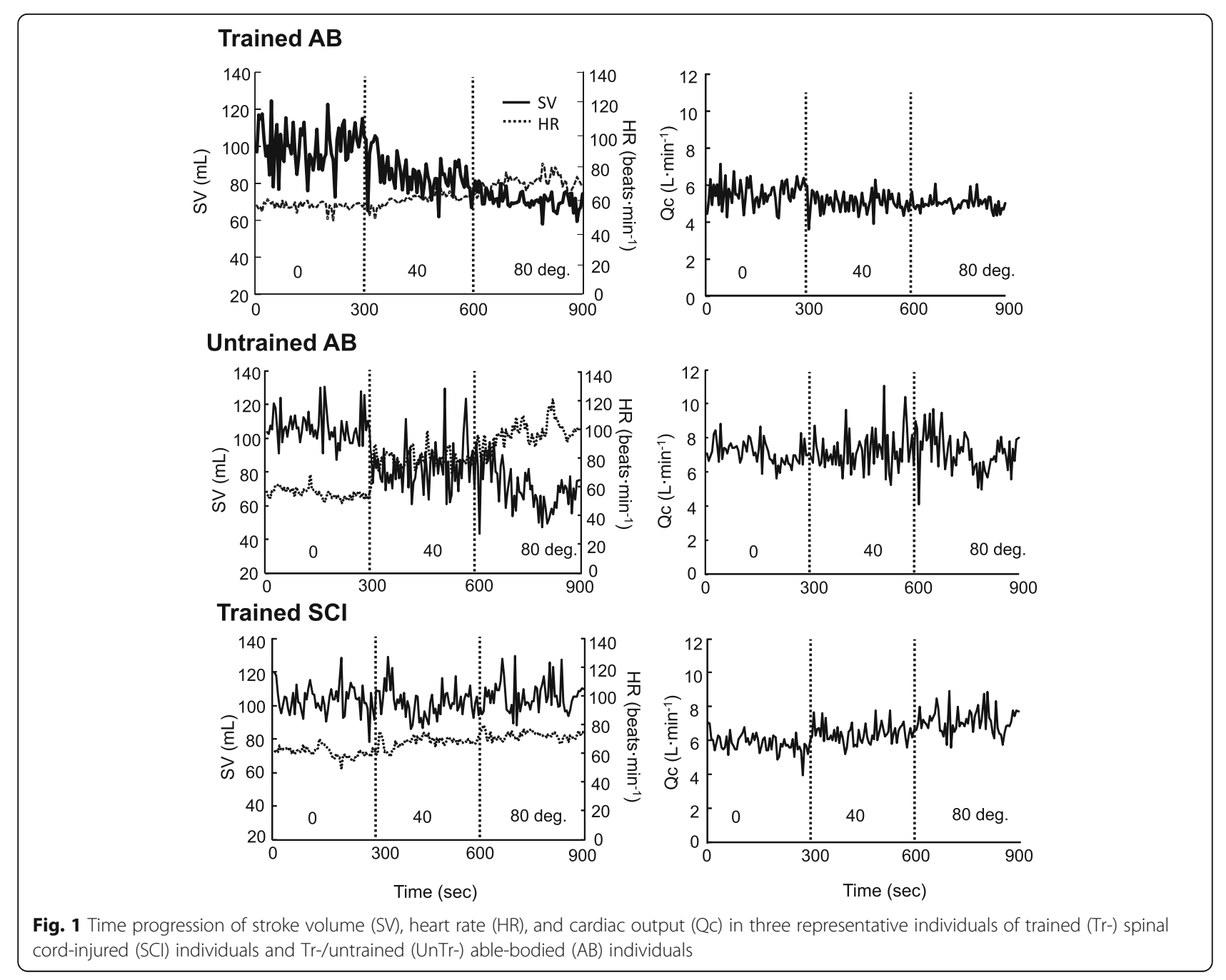




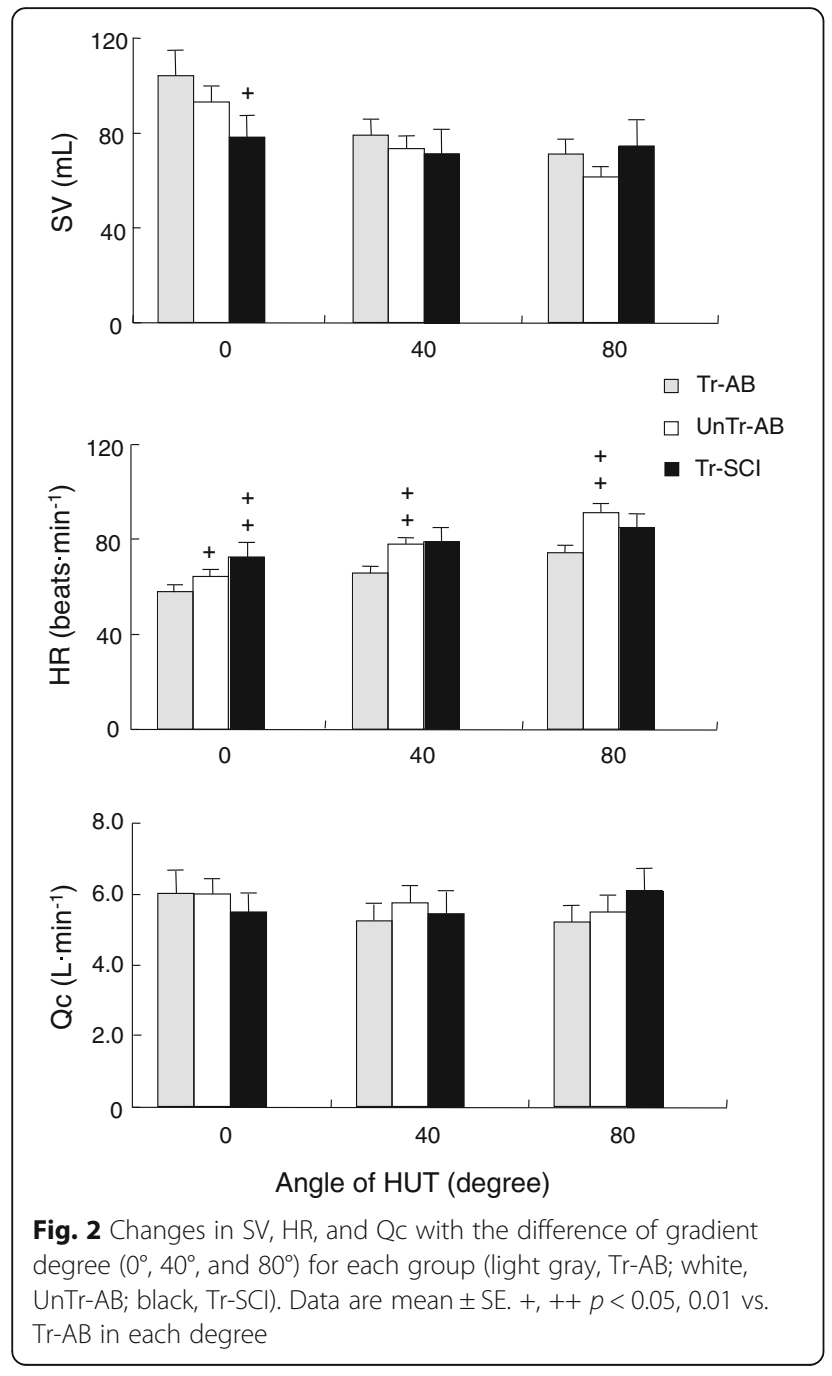

TPR changes were observed in the $\mathrm{Tr}$-SCI group as the gradient increased from $0^{\circ}$ to $40^{\circ}$ and $80^{\circ}$ (Table 2). For all three groups at each gradient, there were no significant differences in any SBP variables.

Figure 3 shows the representative peripheral circulatory responses estimated from $\Delta\left[\mathrm{HbO}_{2}\right], \Delta[\mathrm{HHb}]$, and $\Delta\left[\mathrm{Hb}_{\text {tot }}\right]$ in each group during an orthostatic challenge. $\Delta\left[\mathrm{HbO}_{2}\right], \Delta[\mathrm{HHb}]$, and $\Delta\left[\mathrm{Hb}_{\text {tot }}\right]$ in the gastrocnemius muscle increased greatly as the gradient increased from $0^{\circ}$ to $40^{\circ}$ and $80^{\circ}$ in UnTr-AB subjects. Interestingly, there was a significant difference in $\Delta\left[\mathrm{HbO}_{2}\right]$ between $\mathrm{Tr}-\mathrm{AB}$ and UnTr-AB subjects at $40^{\circ}(\mathrm{Tr}-\mathrm{AB},-0.01 \pm$ 0.08; UnTr-AB, $0.62 \pm 0.21 \mu \mathrm{mol} \mathrm{dL}{ }^{-1}, F_{(2,20)}=3.49, p<$ 0.05 , Fig. 4). However, the average $\Delta\left[\mathrm{HbO}_{2}\right]$ in the $\mathrm{Tr}-\mathrm{SCI}$ subjects remained stable at all gradients.

In all three groups, there was a common trend in which the $\Delta[\mathrm{HHb}]$ proportionally increased with the gradients, and a significant difference in $\Delta[\mathrm{HHb}]$ was observed between $0^{\circ}$ and $80^{\circ}$ even in the $\mathrm{Tr}$-SCI group $\left(F_{(2,20)}=3.55, p<0.01\right.$, Fig. 4). In particular, the $\Delta[\mathrm{HHb}]$
Table 2 Vascular dynamic responses during three stages of the tilt table

\begin{tabular}{|c|c|c|c|}
\hline & $0^{\circ}$ (rest) & $40^{\circ}$ & $80^{\circ}$ \\
\hline \multicolumn{4}{|l|}{$\operatorname{Tr}-\mathrm{AB}$} \\
\hline HR (beats $\min ^{-1}$ ) & $58 \pm 3$ & $66 \pm 3^{* *}$ & $74 \pm 3 * *$ \\
\hline $\mathrm{SV}\left(\mathrm{mL} \mathrm{min}^{-1}\right)$ & $104 \pm 11$ & $79 \pm 6 *$ & $71 \pm 6 *$ \\
\hline Qc $\left(L \min ^{-1}\right)$ & $6.0 \pm 0.6$ & $5.2 \pm 0.5$ & $5.2 \pm 0.5$ \\
\hline $\mathrm{SBP}(\mathrm{mmHg})$ & $116 \pm 2$ & $117 \pm 3$ & $118 \pm 4$ \\
\hline $\mathrm{DBP}(\mathrm{mmHg})$ & $61 \pm 2$ & $67 \pm 3$ & $69 \pm 3$ \\
\hline MAP $(\mathrm{mmHg})$ & $80 \pm 3$ & $83 \pm 4$ & $85 \pm 3 *$ \\
\hline $\operatorname{TPR}\left(\mathrm{mmHg} \mathrm{L} \mathrm{L}^{-1} \mathrm{~min}^{-1}\right)$ & $15 \pm 3$ & $17 \pm 3$ & $17 \pm 2$ \\
\hline \multicolumn{4}{|l|}{ UnTr-AB } \\
\hline HR (beats $\min ^{-1}$ ) & $64 \pm 2$ & $78 \pm 2^{* *}$ & $91 \pm 4^{* *}$ \\
\hline $\mathrm{SV}\left(\mathrm{mL} \mathrm{min}^{-1}\right)$ & $93 \pm 6$ & $73 \pm 5^{* *}$ & $62 \pm 4^{* *}$ \\
\hline Qc $\left(L \min ^{-1}\right)$ & $5.9 \pm 0.4$ & $5.7 \pm 0.4$ & $5.6 \pm 0.4$ \\
\hline $\mathrm{SBP}(\mathrm{mmHg})$ & $101 \pm 10$ & $109 \pm 7$ & $113 \pm 5$ \\
\hline $\mathrm{DBP}(\mathrm{mmHg})$ & $58 \pm 6$ & $67 \pm 4 * *$ & $72 \pm 2 * *$ \\
\hline MAP $(\mathrm{mmHg})$ & $76 \pm 7$ & $85 \pm 5^{* *}$ & $90 \pm 3 * *$ \\
\hline $\operatorname{TPR}\left(\mathrm{mmHg} \mathrm{L} \mathrm{L}^{-1} \mathrm{~min}^{-1}\right)$ & $14 \pm 1$ & $16 \pm 2$ & $17 \pm 2$ \\
\hline \multicolumn{4}{|l|}{$\mathrm{Tr}-\mathrm{SCl}$} \\
\hline HR (beats $\min ^{-1}$ ) & $73 \pm 6$ & $79 \pm 6^{* *}$ & $85 \pm 6^{* *}$ \\
\hline $\mathrm{SV}\left(\mathrm{mL} \mathrm{min}^{-1}\right)$ & $78 \pm 9$ & $71 \pm 10$ & $74 \pm 11$ \\
\hline Qc $\left(L \min ^{-1}\right)$ & $5.5 \pm 0.5$ & $5.4 \pm 0.6$ & $6.1 \pm 0.6$ \\
\hline $\mathrm{SBP}(\mathrm{mmHg})$ & $115 \pm 4$ & $118 \pm 2$ & $124 \pm 4$ \\
\hline $\mathrm{DBP}(\mathrm{mmHg})$ & $70 \pm 2$ & $73 \pm 1$ & $76 \pm 2$ \\
\hline MAP (mmHg) & $85 \pm 3$ & $88 \pm 1$ & $92 \pm 2$ \\
\hline $\operatorname{TPR}\left(\mathrm{mmHg} \mathrm{L} \mathrm{L}^{-1} \mathrm{~min}^{-1}\right)$ & $16 \pm 2$ & $17 \pm 2$ & $16 \pm 2$ \\
\hline
\end{tabular}

Heart rate (HR), stroke volume (SV), cardiac output (Qc), systolic blood pressure (SBP), diastolic blood pressure (DBP), mean arterial pressure (MAP), and total peripheral resistance (TPR) were determined. Data are shown by mean \pm SE *** $p<0.05,0.01$ vs. 0 degree in each group, respectively

in the $\operatorname{Tr}-\mathrm{AB}$ group $\left(1.74 \pm 0.23 \mu \mathrm{mol} \mathrm{dL}^{-1}\right)$ increased compared to the $\mathrm{Tr}-\mathrm{SCI}$ group at $80^{\circ}$ ( $\mathrm{Tr}-\mathrm{SCI}, 0.45 \pm$ $\left.0.07 \mu \mathrm{mol} \mathrm{dL}{ }^{-1}, F_{(2,20)}=3.49, p<0.01\right)$ and compared to the UnTr-AB group $\left(0.73 \pm 0.08 \mu \mathrm{mol} \mathrm{dL}-1, F_{(2,20)}=\right.$ $3.49, p<0.05)$.

$\Delta\left[\mathrm{Hb}_{\text {tot }}\right]$, which was the sum of $\Delta[\mathrm{HHb}]$ and $\Delta\left[\mathrm{HbO}_{2}\right]$, was mostly reflected in the alterations in $\Delta[\mathrm{HHb}]$ and was significantly increased as the tilt gradient increased (Fig. 4). At $80^{\circ} \mathrm{HUT}$, the $\Delta\left[\mathrm{Hb}_{\text {tot }}\right]$ in the $\mathrm{Tr}-\mathrm{AB}$ group $\left(1.53 \pm 0.16 \mu \mathrm{mol} \mathrm{dL}{ }^{-1}\right)$ was shown to be significantly greater than those in the UnTr-AB and $\mathrm{Tr}$-SCI groups $\left(1.05 \pm 0.25, \quad 0.52 \pm 0.22, \mu \mathrm{mol} \mathrm{dL}-1, F_{(2,20)}=3.40, p<\right.$ $0.05, p<0.01$, respectively). Compared to the UnTr-AB group, significantly smaller $\Delta\left[\mathrm{Hb}_{\text {tot }}\right]$ values were observed in Tr-SCI group $\left(F_{(2,20)}=3.49, p<0.05\right)$. Thus, the status of the change ( $\mathrm{AB}$ vs. $\mathrm{SCI})$ could be reflected by $\Delta[\mathrm{HHb}]$ and $\Delta\left[\mathrm{HbO}_{2}\right]$ responses to orthostatic stress associated with central circulation. 


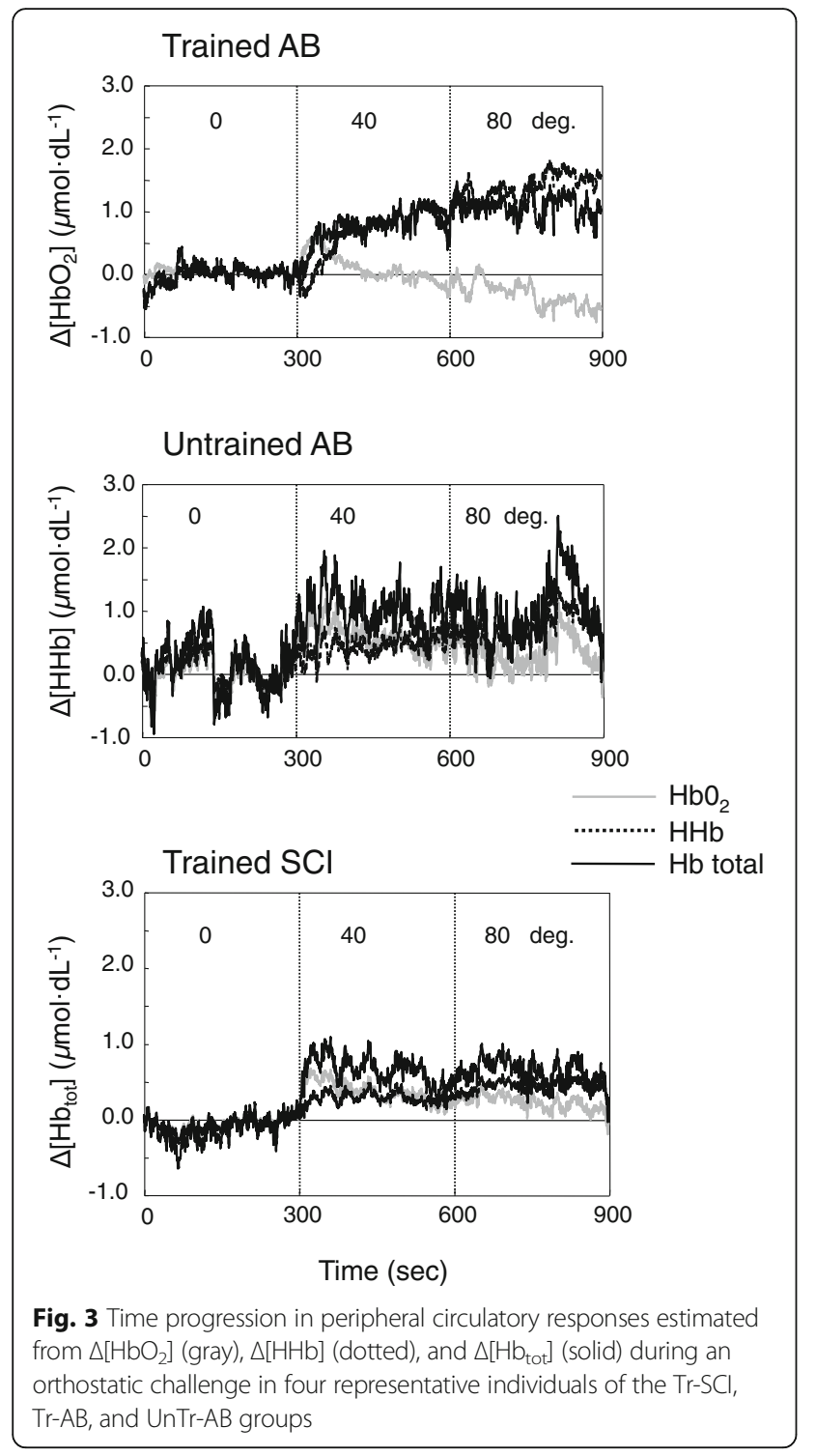

\section{Discussion}

The present study examined the differential changes in central and peripheral circulatory responses to an orthostatic challenge in the Tr-SCI group in comparison with the $\operatorname{Tr}-\mathrm{AB}$ and $\mathrm{UnTr}-\mathrm{AB}$ groups at different tilt gradients $\left(0^{\circ}, 40^{\circ}\right.$, and $\left.80^{\circ}\right)$. Regarding the peripheral circulation corresponding to the central circulation, small alterations of $\Delta[\mathrm{HHb}]$ and $\Delta\left[\mathrm{Hb}_{\text {tot }}\right]$ from $0^{\circ}$ to $40^{\circ}$ to $80^{\circ}$ were shown by the Tr-SCI group. Significantly greater increases of $\Delta[\mathrm{HHb}]$ and $\Delta\left[\mathrm{Hb}_{\text {tot }}\right]$ occurred in the Tr- $\mathrm{AB}$ group $(p<0.05)$, corresponding to significantly decreased $\mathrm{SV}$ and increased $\mathrm{HR}$ in both $\mathrm{AB}$ groups. Therefore, trained individuals with spinal cord injuries (Tr-SCI) are capable of maintaining their MAP even in response to an orthostatic challenge, and the mechanism underlying this maintenance of MAP may be similar to or the same

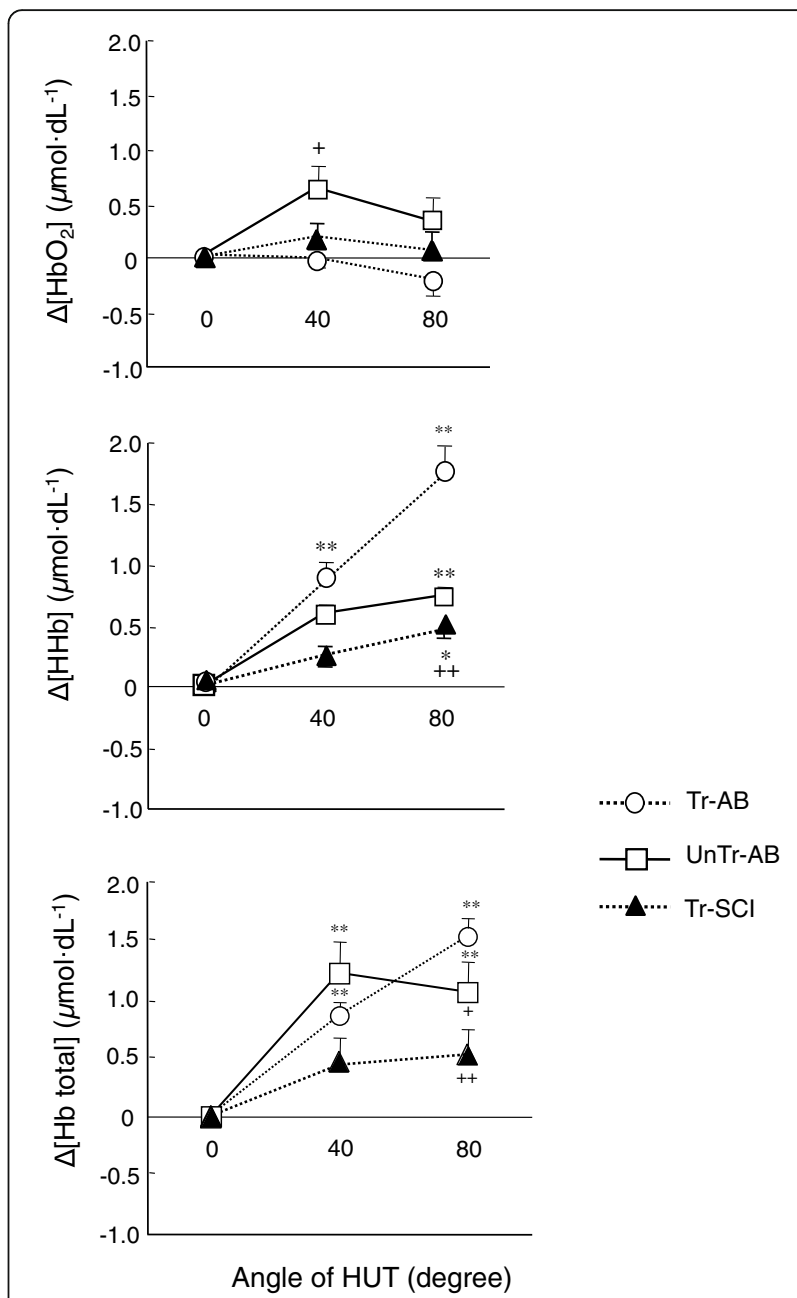

Fig. 4 Changes in peripheral circulatory responses, $\Delta\left[\mathrm{HbO}_{2}\right], \Delta[\mathrm{HHb}]$, and $\Delta\left[\mathrm{Hb}_{\text {tot }}\right]$ with the difference of gradient degree $\left(0^{\circ}, 40^{\circ}\right.$, and $\left.80^{\circ}\right)$ for each group (white circle: $\operatorname{Tr}-\mathrm{AB}$, white square: UnTr-AB, black trianle: Tr-SCI). Data are mean $\pm S E$. ${ }^{*},{ }^{* *} p<0.05,0.01$ vs. 0 gradient degree at each group. $+,++p<0.05,0.01 \mathrm{vs}$. Tr-AB

as that by which peripheral vasoconstriction and less blood pooling are elicited in paraplegic limbs.

\section{Hemodynamic responses to an orthostatic challenge}

In $\mathrm{Tr}$-SCI group, the HR in a supine position was significantly higher than that in the two $\mathrm{AB}$ groups. It was reported previously that paraplegics had a higher HR in a supine position compared to able-bodied controls [22]. In another study, SCI individuals exhibited significantly higher resting values of plasma renin and catecholamines (particularly epinephrine) than able-bodied individuals [23]. Among higher HR responders in ablebodied individuals, the plasma norepinephrine responses were all greater than those exhibited by individuals with lower HR responses [24]. We therefore speculate that in the present $\mathrm{Tr}$-SCI group, the cardiovascular effects of 
chronically elevated vasoactive hormones might play a very significant role in setting the mean HR (Fig. 2).

In both $A B$ groups of the present study, significantly increased HR and inversely decreased SV were proportionally observed in association with increased HUT from $0^{\circ}$ to $80^{\circ}$, whereas the $\mathrm{Tr}$-SCI group exhibited less change in SV at all degrees of tilt. The resultant Qc showed no significant differences among any of the groups or gradient degrees. In addition, it has been suggested that in the $\mathrm{Tr}$-SCI group, the venous return blood volume remained constant with less blood pooling under orthostatic stress. Sympathetic neurogenic vasoconstriction is quantitatively important in terms of successful responses to orthostasis [25]. Aslan et al. indicated that an SCI results in decreased stimulation of arterial baroreceptors and less engagement of feedback control [26].

However, in the present investigation, the $\mathrm{Tr}-\mathrm{SCI}$ group was able to maintain their MAP during HUT tests even though their responses showed no significant changes, whereas in the $\mathrm{AB}$ groups, the MAP and $\mathrm{DBP}$ were significantly increased at increased gradient degrees. This suggests that the baroreflex sensitivity in the Tr-SCI group might not be activated because less venous blood pools from the limbs to the thoracic region [27]. Tr-SCI group was characterized by slightly but significantly increased $\Delta[\mathrm{HHb}]$, even though the HR and the BP responses were not greatly altered. This might be due to the maintenance of residual sympathetically mediated vasoconstriction for paraplegic individuals with lesions below the Th6 level of the incomplete spinal cord.

\section{Peripheral vascular responses estimated using NIRS}

At an $80^{\circ}$ tilt, the $\Delta[\mathrm{HHb}]$ in the $\mathrm{Tr}-\mathrm{AB}$ group was increased approximately threefold compared to the $\mathrm{Tr}$-SCI and compared to the UnTr-AB groups; the $\Delta\left[\mathrm{Hb}_{\text {tot }}\right]$ was mostly reflected in the alterations in $\Delta[\mathrm{HHb}]$. In previous studies involving SCI individuals, the central blood volume was found to be decreased by approximately $20 \%$ compared to healthy subjects at supine rest [28] because there is less blood pooling volume and/or fewer blood vessels in the lower limb muscles [29]. The former possibility would result from the increasing leg vascular resistance in individuals with an SCI during HUT in order to maintain the mean arterial pressure [30]. The latter possibility would result from the gastrocnemius circulation volume per se being reduced due to the atrophy of the vascular vessels [29].

The vascular atrophy of the peripheral vascular bed was confirmed by some studies that observed a smaller femoral artery (FA) or reduced capillary supply in SCI individuals compared to able-bodied subjects [3, 7]. Consistent with the reduced FA diameter, the FA blood flow in SCI individuals (from 220 to $150 \mathrm{~mL} \mathrm{~min}^{-1}$ ) during HUT also appeared to be reduced when compared with values reported in able-bodied individuals (from 350 to $230 \mathrm{~mL} \mathrm{~min}^{-1}$ ) [9]. Indeed, the increase in leg vascular resistance during HUT not only in SCI individuals but also in healthy controls was unaffected during an intra-arterial infusion of phentolamine (an adrenergic antagonist), irrespective of whether the sympathetic baroreflex was intact [31].

The Tr-SCI group was characterized by slightly but significantly increased $\Delta[\mathrm{HHb}]$ at $80^{\circ} \mathrm{HUT}$ compared to $0^{\circ}$, demonstrating that even the trained $\mathrm{SCI}$ individuals also exhibited venous distensibility and venous capacity in the lower limbs [9]. In addition, differences in $\Delta\left[\mathrm{Hb}_{\text {tot }}\right]$ and $\Delta[\mathrm{HHb}]$ between our $\mathrm{Tr}-\mathrm{AB}$ and UnTr-AB individuals might be due to the increased number of vessels resulting from the $\mathrm{Tr}-\mathrm{AB}$ subjects' endurance exercise training. This is thought to be caused by the volume of blood pooling having increased much more in the $\mathrm{Tr}-\mathrm{AB}$ group than in UnTr-AB group because endurance exercise training imparts a powerful stimulus for vascular remodeling [32].

\section{Study limitations}

In general, the 20- and 30-year-old subjects would be defined as young individuals. The age difference between the trained SCI and two AB groups is not very important, because the metabolism in working muscles would be similar in potential between a 30-year-old and a 20-year-old [1].

The continuous-wave (CW)-NIRS we used in the present study assesses relative rather than absolute $\left[\mathrm{HbO}_{2}\right],[\mathrm{HHb}]$, and $\left[\mathrm{Hb}_{\text {tot }}\right]$ values, which may have obscured the underlying response(s). The ATT in the medial gastrocnemius muscle region averaged $8.7 \pm$ $0.8 \mathrm{~mm}$ in the $\mathrm{Tr}$-SCI group, which might influence the optic strength of each wavelength in the $\mathrm{Tr}$-SCI group. Thus, there may be a possibility that we underestimated the optical coefficients in the cases of $>5 \mathrm{~mm}$ ATT [33]. The ATT in young subjects were mostly $<5 \mathrm{~mm}$, as observed in our other study [34], even though the ATT in the two present AB groups could not be measured.

By contrast, Binzoni et al. reported that the deoxygenation $[\mathrm{HHb}$ ] of CW-NIRS did not vary as a function of the fat layer, whereas the oxygenation $\left[\mathrm{HbO}_{2}\right]$ was definitely higher in muscle than in fat, as shown by the lower ATT data [35]. In the present study, as the larger alterations in $\Delta[\mathrm{HHb}]$ and $\Delta\left[\mathrm{Hb}_{\text {tot }}\right]$ were observed during HUT, the clinical implications for CW-NIRS might have been less influenced.

Since we did not measure EMG in paralyzed limbs as muscle spasms were often assessed in previous studies [36], thus, we could not quantify muscle activity (e.g., spasm). This is one of the technical limitations in the present study; however, we carefully observed and did 
not find any symptoms of muscle spasm in all patients. Despite this, future studied should be warranted.

\section{Conclusions}

In a supine posture, the Tr-SCI group had significantly higher $\mathrm{HR}$ and lower $\mathrm{SV}$ values compared to the two $\mathrm{AB}$ groups. During subsequent HUT tests, Tr-SCI group exhibited less decreased SV and small alterations of $\Delta[\mathrm{HHb}]$ and $\Delta\left[\mathrm{Hb}_{\text {tot }}\right]$ compared to those in both $\mathrm{AB}$ groups. MAP also did not significantly increase as the tilting increased from $0^{\circ}$ to $80^{\circ}$. These results suggest that there is less blood pooling due to peripheral vasoconstriction and fewer blood vessels in paraplegic lower limbs of exercise-trained SCI individuals. These results are associated with less change in SV in response to an orthostatic challenge.

\section{Abbreviations}

$\Delta\left[\mathrm{HbO}_{2}\right]$ : Oxyhemoglobin; $\Delta\left[\mathrm{Hb}_{\text {tot }}\right]$ : Total hemoglobin:

$\Delta[\mathrm{HHb}]$ : Deoxyhemoglobin; AB: Able-bodied individual; HR: Heart rate; HUT: Head-up tilt; MAP: Mean arterial pressure; Qc: Cardiac output; SBP \& DBP: Systolic and diastolic blood pressures; SCl: Spinal cord-injured individual; SV: Stroke volume; TPR: Total peripheral resistance; Tr-, UnTr-: Trained-, untrained individuals

\section{Acknowledgements}

We would like to thank the expert technical assistance by the academic staffs (M Iwamizu, C Murakami, M Arima).

\section{Funding}

This study was supported in part by Kumamoto Frontier Science Promotion (to YF), Sasagawa Heath Science Grant (to MYE), and Grants-in-Aid for Science Research from the Ministry of Education and Science of Japan (22370091 to YF).

\section{Availability of data and materials}

The datasets used and/or analyzed during the current study are available from the corresponding author on reasonable request.

\section{Authors' contributions}

$\mathrm{MI}$ conceived and designed the study. MYE and MI managed the data collection. MYE analyzed the data with MY. YF and TH contributed to the physiological and clinical interpretations in the present study. MI and YF drafted the initial manuscript with important intellectual contributions from all co-authors. All authors read and approved the final manuscript.

\section{Ethics approval and consent to participate}

The experimental protocol was approved by the ethics committee of the Institutional Review Board of the Prefectural University of Kumamoto. All subjects provided written consent for their participation after they were fully informed about the study. The investigation was performed in compliance with the Declaration of Helsinki.

\section{Consent for publication}

We fully understand and agree to all the terms and conditions stated here by you. Thank you for your consideration of my submitted paper.

\section{Competing interests}

The authors declare that they have no competing interests.

\section{Publisher's Note}

Springer Nature remains neutral with regard to jurisdictional claims in published maps and institutional affiliations.

\section{Author details}

'Department of Physiology, Kumamoto University Graduate School of Life Sciences, 4-24-1, Kuhonji Chuou-ku, Kumamoto 862-0976, Japan. ${ }^{2}$ Department of Exercise Science and Physiology, Faculty of Human Culture and Science, Prefectural University of Hiroshima, Hiroshima, Japan. ${ }^{3}$ Laboratory of Sports Medicine, Faculty of Health and Sport Science, Doshisha University, Kyoto, Japan. ${ }^{4}$ Laboratory of Environmental Physiology, Faculty of Environmental and Symbiotic Sciences, Prefectural University of Kumamoto, Kumamoto, Japan. ${ }^{5}$ Laboratory of Environmental Physiology, Faculty of Health and Sport Science, Doshisha University, Kyoto, Japan.

Received: 14 February 2018 Accepted: 13 September 2018

Published online: 29 September 2018

\section{References}

1. Fukuoka Y, Endo M, Kagawa H, Itoh M, Nakanishi R. Kinetics and steady-state of $\mathrm{VO} 2$ responses to arm exercise in trained spinal cord injury humans. Spinal Cord. 2002:40:631-8.

2. De Groot PC, van Dijk A, Dijk E, Hopman MT. Preserved cardiac function after chronic spinal cord injury. Arch Phys Med Rehabil. 2006:87:1195-2000.

3. Hopman MT, Groothuis JT, Flendrie M, Gerrits HL, Houtman S. Increased vascular resistance in paralyzed legs after spinal cord injury is reversible by training. J Appl Physiol. 2002;93:1966-72.

4. Chilibeck PD, Jeon J, Weiss C, Bell G, Burnham R. Histochemical changes in muscle of individuals with spinal cord injury following functional electrical stimulated exercise training. Spinal Cord. 1999:37:264-8.

5. De Groot PC, Van Kuppevelt DH, Pons C, Snoek G, Van Der Woude LH, Hopman MT. Time course of arterial vascular adaptations to inactivity and paralyses in humans. Med Sci Sports Exerc. 2003;35:1977-85.

6. Hopman MT, van Asten WN, Oeseburg B. Changes in blood flow in the common femoral artery related to inactivity and muscle atrophy in individuals with long-standing paraplegia. Adv Exp Med Biol. 1996;388:379-83.

7. Nash MS, Montalvo BM, Applegate B. Lower extremity blood flow and responses to occlusion ischemia differ in exercise-trained and sedentary tetraplegic persons. Arch Phys Med Rehabil. 1996:77:1260-5.

8. Faghri PD, Yount JP, Pesce WJ, Seetharama S, Votto JJ. Circulatory hypokinesis and functional electric stimulation during standing in persons with spinal cord injury. Arch Phys Med Rehabil. 2001;82:1587-95.

9. Groothuis JT, Boot CR, Houtman S, van Langen H, Hopman MT. Leg vascular resistance increases during head-up tilt in paraplegics. Eur J Appl Physiol. 2005;94:408-14.

10. Theisen D, Vanlandewijck Y, Sturbois $X$, Francaux M. Blood distribution adaptations in paraplegics during posture changes: peripheral and central reflex responses. Eur J Appl Physiol. 2000:81:463-9.

11. Zwiren LD, Bar-Or O. Responses to exercise of paraplegics who differ in conditioning level. Med Sci Sports. 1975;7:94-8.

12. Davis GM, Shephard RJ. Cardiorespiratory fitness in highly active versus inactive paraplegics. Med Sci Sports Exerc. 1988:20:463-8.

13. Maynard FM Jr, Bracken MB, Creasey G, Ditunno JF Jr, Donovan WH, Ducker TB, Garber SL, Marino RJ, Stover SL, Tator CH, Waters RL Wilberger JE, Young W. International standards for neurological and functional classification of spinal cord injury. Am spinal injury assoc Spinal Cord. 1997;35:266-74.

14. Yamabata S, Shiraishi H, Munechika M, Fukushima H, Fukuoka Y, Hojo T, Shirayama T, Horii M, Matoba S, Kubo T. Effects of electrical stimulation therapy on the blood flow in chronic critical limb ischemia patients following regenerative therapy. SAGE Open Med. 2016;22. https://doi.org/10. 1177/2050312116660723

15. McCully KK, Halber C, Posner JD. Exercise-induced changes in oxygen saturation in the calf muscles of elderly subjects with peripheral vascular disease. J Gerontol. 1994:49:B128-34.

16. Qu MH, Zhang YJ, Webster JG, Tompkins WJ. Motion artifact from spot and band electrodes during impedance cardiography. IEEE Trans Biomed Eng. 1986;33:1029-36.

17. Miyamoto Y, Higuchi J, Abe Y, Hiura T, Nakazono Y, Mikami T. Dynamics of cardiac output and systolic time intervals in supine and upright exercise. J Appl Physiol. 1983;55:1674-81.

18. Kashima S. Spectroscopic measurement of blood volume and its oxygenation in a small volume of tissue using red laser lights and differential calculation between two point detections. Opt Laser Technol. 2003:35:485-9. 
19. Binzoni T, Cerretelli P, Ferrari M, Delpy D. Metabolic studies of human skeletal muscle by near infrared spectroscopy: possible applications in space research. Int J Sports Med. 1997;18(Suppl 4):S312-4.

20. Jacobs PL, Mahoney ET, Robbins A, Nash M. Hypokinetic circulation in persons with paraplegia. Med Sci Sports Exerc. 2002;34:1401-7.

21. Raymond J, Davis GM, Climstein M, Sutton JR. Cardiorespiratory responses to arm cranking and electrical stimulation leg cycling in people with paraplegia. Med Sci Sports Exerc. 1999;31:822-8.

22. Wecht JM, De Meersman RE, Weir JP, Spungen AM, Bauman WA. Cardiac autonomic responses to progressive head-up tilt in individuals with paraplegia. Clin Auton Res. 2003;13:433-8.

23. Hogencamp CE, Knapp CF, Aslan S, Hartman A, Evans JM. Role of skin perfusion and fluid volume shifts in regulating blood pressure following spinal cord injury (Abstract). FASEB J. 2004;18:A662.

24. Ramirez-Marrero FA, Charkoudian N, Hart EC, Schroeder D, Zhong L, Eisenach $\mathrm{JH}$, Joyner MJ. Cardiovascular dynamics in healthy subjects with differing heart rate to tilt. J Appl Physiol. 2008;105:1448-53.

25. Cooper VL, Hainsworth R. Carotid baroreceptor reflexes in humans during orthostatic stress. Exp Physiol. 2001:86:677-81.

26. Aslan SC, Randall DC, Donohue KD, Knapp CF, Patwardhan AR, McDowell SM, Taylor RF, Evans JM. Blood pressure regulation in neurally intact human vs. acutely injured paraplegic and tetraplegic patients during passive tilt. Am J Physiol Regul Integr Comp Physiol. 2007;292:R1146-57.

27. Di Rienzo M, Parati G, Castiglioni P, Tordi R, Mancia G, Pedotti A. Baroreflex effectiveness index: an additional measure of baroreflex control of heart rate in daily life. Am J Physiol Regul Integr Comp Physiol. 2001;280:R744-51.

28. Raymond J, Davis GM, Bryant G, Clarke J. Cardiovascular responses to an orthostatic challenge and electrical-stimulation-induced leg muscle contractions in individuals with paraplegia. Eur J Appl Physiol. 1999;80:205-12.

29. Hopman MT. Circulatory responses during arm exercise in individuals with paraplegia. Int J Sports Med. 1994;15:126-31.

30. Groothuis JT, Boot CR, Houtman S, van Langen H, Hopman MT. Does peripheral nerve degeneration affect circulatory responses to head-up tilt in spinal cord-injured individuals? Clin Auton Res. 2005;15:99-106.

31. Groothuis JT, Thijssen HJ, Lenders WM, Deinum J, Hopman MT. Leg vasoconstriction during head-up tilt in patients with autonomic failure is not abolished. J Appl Physiol. 2011:110:416-22.

32. D'Angelo G, Meininger GA. Transduction mechanisms involved in the regulation of myogenic activity. Hypertension. 1994;23:1096-105.

33. Yang Y, Soyemi OO, Landry MR, Soller BR. Influence of a fat layer on the near infrared spectra of human muscle: quantitative analysis based on twolayered Monte Carlo simulations and phantom experiments. Opt Express. 2005:13:1570-9.

34. Koga S, Poole DC, Fukuoka Y, Ferreira LF, Kondo N, Ohmae E, Barstow TJ. Methodological validation of the dynamic heterogeneity of muscle deoxygenation within the quadriceps during cycle exercise. Am J Physiol Regul Integr Comp Physiol. 2011;301:R534-41.

35. Binzoni T, Quaresima V, Barattelli G, Hiltbrand E, Gurke L, Terrier F, Cerretelli P, Ferrari M. Energy metabolism and interstitial fluid displacement in human gastrocnemius during short ischemic cycles. J Appl Physiol. 1998:85:1244-51.

36. Thijssen DH, Steendijk S, Hopman MT. Blood redistribution during exercise in subjects with spinal cord injury and controls. Med Sci Sports Exerc. 2009; 41:1249-54.

Ready to submit your research? Choose BMC and benefit from:

- fast, convenient online submission

- thorough peer review by experienced researchers in your field

- rapid publication on acceptance

- support for research data, including large and complex data types

- gold Open Access which fosters wider collaboration and increased citations

- maximum visibility for your research: over $100 \mathrm{M}$ website views per year

At $\mathrm{BMC}$, research is always in progress.

Learn more biomedcentral.com/submissions 